\title{
Pasión. ruptura y humanismo: la poesía centroamericana contemporánea escrita por mujeres
}

Passion. rupture and humanism: contemporaneous Central American poetry written by women.

\author{
Ericka Calderón Rojas \\ Universidad Nacional, Sede Central \\ Heredia, Costa Rica \\ ericka.calderon.rojas@una.cr
}

Resumen: Históricamente las mujeres han sido subvaloradas en los distintos ámbitos del quehacer humano; la literatura no ha sido la excepción. No obstante, diversas y de gran calidad han sido las creaciones femeninas en este ámbito, tanto a nivel mundial, latinoamericano y centroamericano, especialmente en la época contemporánea. Se evidencia en este artículo la creación femenina centroamericana contemporánea como una ruptura al estatuto patriarcal, tan implantado en las sociedades desde épocas primigenias. Dicha ruptura, contestataria, se realiza a través de la expresión de la corporeidad y la pasión; relacionadas ambas con el concepto del humanismo.

Palabras clave: feminismo, literatura, Centroamérica contemporánea, patriarcado, ruptura, humanismo.

Abstract: Historically, women have been undervalued in the various fields of human endeavor, and literature has not been an exception. However, women's creations in this area have been diverse and of great quality, globally as well as at the Latin and Central America levels, especially 
in contemporary times. This article shows the work of contemporary Central American women as a rupture from the patriarchal statute, so rooted in societies since primeval times. This rupture, a rebellious one, takes place through the expression of corporeality and passion, both related to the concept of humanism.

Keywords: feminism, literature, contemporary Central America, patriarchy, rupture, humanism.

\section{La situación de la poesía centroamericana femenina contemporánea}

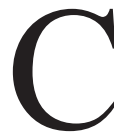

uando hablamos de la poesía centroamericana viene a nuestra mente una serie de nombres, unos altamente conocidos a nivel internacional y otros que apenas han logrado traspasar sus fronteras, tales como los costarricenses Isaac Felipe Azofeifa (1909-1997) y Aquileo J Echeverría (18661909); los nicaragüenses Rubén Darío (1867-1916), José Coronel Urtecho (19061994) y Ernesto Cardenal (1925); el guatemalteco Marco Antonio Flores (1937); el salvadoreño Manlio Argueta (1935); entre otros. Y ese es precisamente el gran dilema, el "entre otros", pues ha sido concebida una relación canónica de la poesía centroamericana a instancias de creadores masculinos, el Autor -con mayúsculay, la mayoría de las veces, las mujeres han sido excluidas -como de muchas otras actividades- del quehacer literario, en especial de la poesía.

No obstante esta problemática, grandes han sido los logros de las mujeres en este campo a nivel mundial, latinoamericano y, por supuesto, centroamericano, eje principal de este estudio.

Más aún, en la época contemporánea -los últimos diez años del siglo veintiunoprolíficas han sido las expresiones femeninas y feministas reflejadas a través de las letras, de la poesía. Desde ahí han logrado desarticularse los grandes hitos -o mitos- del patriarcado, generándose una apropiación intelectual, ideológica y corporal de las mujeres. Por lo tanto, la poesía contemporánea centroamericana $\mathrm{y}$, con mayor ahínco la escrita por mujeres, se constituye como un espacio donde confluyen la libertad, el empoderamiento, la visibilización de las minorías y el descubrimiento de lo propio

Es posible partir de dos hechos radicales que la constituyen como una poesía desde los márgenes: el primero de ellos es el tema de la mujer como escritora. Desde épocas milenarias la institución social llamada patriarcado ha minimizado el potencial de las mujeres, por motivos ideológicos, políticos y de control; de esta 
manera, se reducía el acceso a la educación, lo cual les imposibilitaba ingresar a los llamados círculos de iniciados, a la vida cultural, intelectual y literaria, dominada por los hombres, como ya se ha mencionado. Muestra de ello es el poema épico de finales del siglo XII escrito por Renaud de Montauban, citado por Luisa Ballesteros en La escritora en la sociedad latinoamericana:

Volved a vuestros apartamentos limpios y dorados, quedaos en la sombra, bebed, comed, bordad, teñid la seda pero no os ocupéis de nuestros asuntos.

Nuestro deber es el de luchar con la espada y el intelecto.

¡Silencio!. (Ballesteros, 1994, p. 9)

En los versos señalados se demuestra notoriamente la posición de la mujer: ocuparse de las labores del hogar, mantenerse alejadas de los asuntos de los varones y, claro está, guardar silencio ante las imposiciones de una sociedad recalcitrante y despectiva del género femenino

Por ende, esa tradición, esa herencia patriarcal, ha calado en el inconsciente colectivo, arrastrándose desde el siglo XII -período en que se escribieron los versos citados- hasta nuestras recientes épocas, causando la invisibilización de las mujeres en el plano de la escritura.

Pueden presentarse argumentaciones al respecto, con ideologías de que esos períodos quedaron atrás o que las mujeres han logrado posicionarse por completo al mismo nivel que los hombres; sin embargo, esa una realidad muy distinta a la que vivimos, pues basta mirar los índices de las antologías de poesía centroamericana, como las de Jorge Boccanera, Seymour Menton y Sergio Ramírez, todas ubicadas en los últimos cinco años, para darse cuenta de que sigue siendo más extensa la lista de los poetas que de las poetas ${ }^{1}$. Excluyo de esta situación al texto Con mano de mujer. Antología de poetas centroamericanas contemporáneas (1970-2008), de Magda Zavala.

A modo de ejemplo, en Puertas abiertas. Antología de la poesía centroamericana, publicada en 2011 por Sergio Ramírez, hay una selección de sesenta y seis poetas, de los cuales solamente dieciséis son mujeres; un veinticuatro coma dos por ciento, números disminuidos en comparación con la cantidad de escritores masculinos mencionados. En el caso particular de Costa Rica, se menciona únicamente a Julieta Dobles y Ana Istarú, lo cual es una clasificación mínima en comparación con la cantidad de mujeres escritoras.

1 Se utiliza el término poeta para el género femenino y no poetiza, al considerarse este despectivo desde la teoría de género. 
No quiere esto decir, reitero, que exista una menor cuantía de féminas ni que sus trabajos sean inferiores, sino que, a pesar del momento en que vivimos, donde se plantea una igualdad de géneros, la realidad es de otro tono.

Por lo tanto, aún en tiempos coetáneos sigue considerándose al hombre como el autor frente a las mujeres. Deben estas levantar su voz y desquebrajar el patrón literario establecido desde antaño; he ahí el primer síntoma de ruptura en las creaciones de las mujeres, incluso en las contemporáneas.

El segundo punto de esa escritura desde los márgenes está relacionado con la posición geográfica, política y económica: Centroamérica. Desde los postulados del capitalismo, América Latina es una región empobrecida, subdesarrollada, un tercer mundo. Con base en esa óptica materialista, América Central posee una problemática más acentuada aún, pues es la franja más pobre y menos desarrollada de ese tercer mundo; es decir, se le considera como "el tercer mundo del tercer mundo", metafórica y cruel, sí, pero seriamente hablando.

De ahí que la literatura y las producciones artísticas en general carguen con una dificultad mayor para darse a conocer, dentro del istmo, dentro de América y en el exterior, pensado este como Europa. Basta consultar las antologías, compendios, diccionarios y estudios críticos de literatura latinoamericana para darse cuenta del desconocimiento y poca mención hacia los textos centroamericanos y sus autoras y autores, salvo excepciones, como Rubén Darío.

La poesía centroamericana escrita por mujeres sufre, por ende, una doble marginalidad, al ser estas una minoría en los cánones literarios y al pertenecer a una región tan desconocida a nivel intelectual y artístico. De ahí que su voz deba levantarse con más fuerza, casi hasta gritar, para no ser excluidas del panorama poético.

De estas premisas citadas surge -además de la motivación de este escrito- la propuesta de pasión, ruptura y humanismo en las creaciones poéticas de mujeres en la Centroamérica actual; a continuación, se explicita cada uno de los puntos. 


\section{Pasión en la poesía contemporánea centroamericana escrita por mujeres}

La palabra pasión ha sido interpretada comúnmente como fervor amoroso o sexual, o bien, como lo define la Real Academia Española: “inclinación o preferencia muy vivas de alguien a otra persona". (RAE, 2001, p.1149). Incluso, en una de sus acepciones esta institución de la lengua advierte que la pasión es un estado de latencia del sujeto, es decir, de inactividad.

No obstante, ninguna de esas dilucidaciones es suficiente para explicar la situación aquí descrita. Es más, tampoco bastan para identificar eso que como humanos concebimos como tal; se trata más bien de una verdadera pasión hacia alguien o hacia algo, una vocación profunda, desasosiego, incluso emoción o explosión en la sangre, causa de alegría y de satisfacción

Por ende, se da pie a malas interpretaciones: no se propone la poesía contemporánea centroamericana escrita por mujeres como un amor ciego o infantil hacia otro; por el contrario, se describe de esta manera una carga ideológica y de sensaciones con las cuales están colmadas las producciones de las autoras, relacionadas con la libertad, el empoderamiento a través del placer, el disfrute del cuerpo propio, de ser mujer, como propone Sofía Kerns “el sentirse poderosa y orgullosa de su femineidad, de sí misma”. (Kerns, 2012, s.p)

Encontramos entonces un placer explicitado a través de la corporeidad, no un cuerpo como deleite de otros, de lo masculino, sino para sí misma; el cual no debe ser perfecto y estético desde la óptica patriarcal, mas propio, no materializable y sobre el cual solamente ella tenga posesión, es decir: mi cuerpo.

Recordemos que el patriarcado instituyó a la mujer como una pertenencia del hombre, como un ser subordinado y dependiente, tal y como lo plantea Yadira Calvo en su texto A la mujer por la palabra (1990). Por consiguiente, esa apropiación corporal de la mujer implica, por una parte ruptura y, por otra, apasionarse por sí misma, su situación y la de otras quizá menos afortunadas.

Se eleva esa voz, ese grito en medio de la marginalidad, para decirse presente y en pie de lucha contra la sociedad recalcitrante y excluyente, ya mencionada. Como ejemplos, podemos citar el poema titulado "Y Dios me hizo mujer", de la nicaragüense Gioconda Belli: 
Y Dios me hizo mujer, de pelo largo,

ojos,

nariz y boca de mujer.

Con curvas

y pliegues

y suaves hondonadas

y me cavó por dentro,

me hizo un taller de seres humanos.

Tejió delicadamente mis nervios

y balanceó con cuidado

el número de mis hormonas.

Compuso mi sangre

y me inyectó con ella

para que irrigara

todo mi cuerpo;

nacieron así las ideas,

los sueños,

el instinto.

Todo lo que creó suavemente

a martillazos de soplidos

y taladrazos de amor,

las mil y una cosas que me hacen mujer todos los días

por las que me levanto orgullosa

todas las mañanas

y bendigo mi sexo. (Belli, 2006: 76)

Asimismo, un poema de Laura Fuentes Belgravçe, escritora costarricense, intitulado "Soy esa otra":

Soy esa otra,

la que huele a hierba y manantial

al incendiar su pecho

de mar.

Soy terremoto,

guerra,

animal convulso

de la historia.

Costilla ineludible

de la lluvia,

heredera del grito

iracundo de la tierra.

Me desbordo 


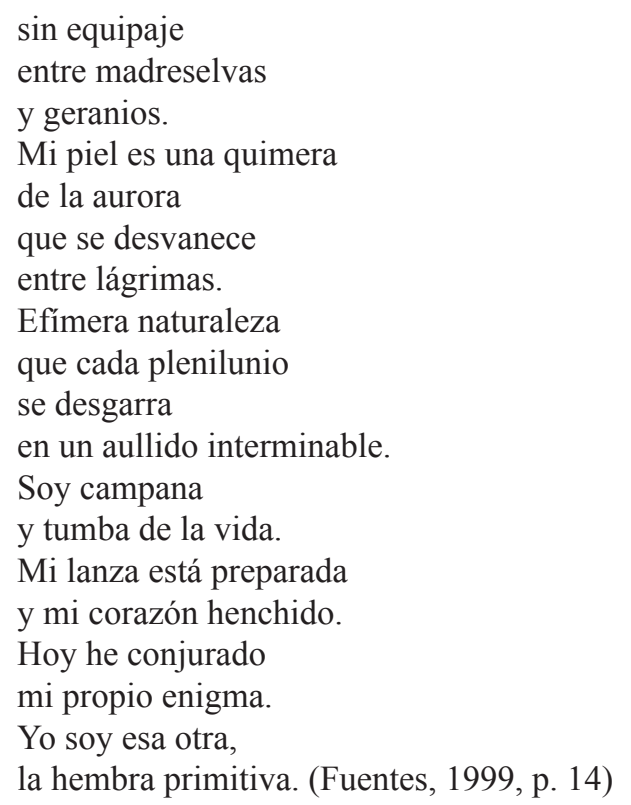

Se evidencia en ambos poemas la pasión por el ser, el ser femenino: el cuerpo propio ligado al placer de la existencia y sus características naturales. De esta manera se plasma a través de la escritura femenina centroamericana contemporánea una ruptura de la concepción patriarcal del cuerpo femenino, pertenencia y objeto del deleite sexual masculino, al darse el empoderamiento a través de la voz, el posicionamiento escritural, el entendido de la mujer como ser individual, pleno, intelectual y visibilizado través de su cuerpo y sus deseos.

Por otro lado, el empoderamiento corporal, del ser, el comportarse como un sujeto autónomo y alejado de los patrones impuestos por el patriarcado pasa por el deleite de la sexualidad, en primera instancia y de la preñez, en segunda.

No se trata en este caso particular de la maternidad como la función intrínseca del ser femenino desde los conceptos patriarcales: producir los hombres de la patria y las mujeres que los sirvan. Por el contrario, de la concepción como decreto propio: yo quiero ser madre, no es que debo, es que quiero. De esta forma, a través de la fecundidad se demuestra al sujeto femenino empoderado de su cuerpo, de sus decisiones y de sus deseos. Como ejemplo pueden mencionarse los versos de la costarricense Ana Istarú en su texto titulado "Ábrete sexo": 


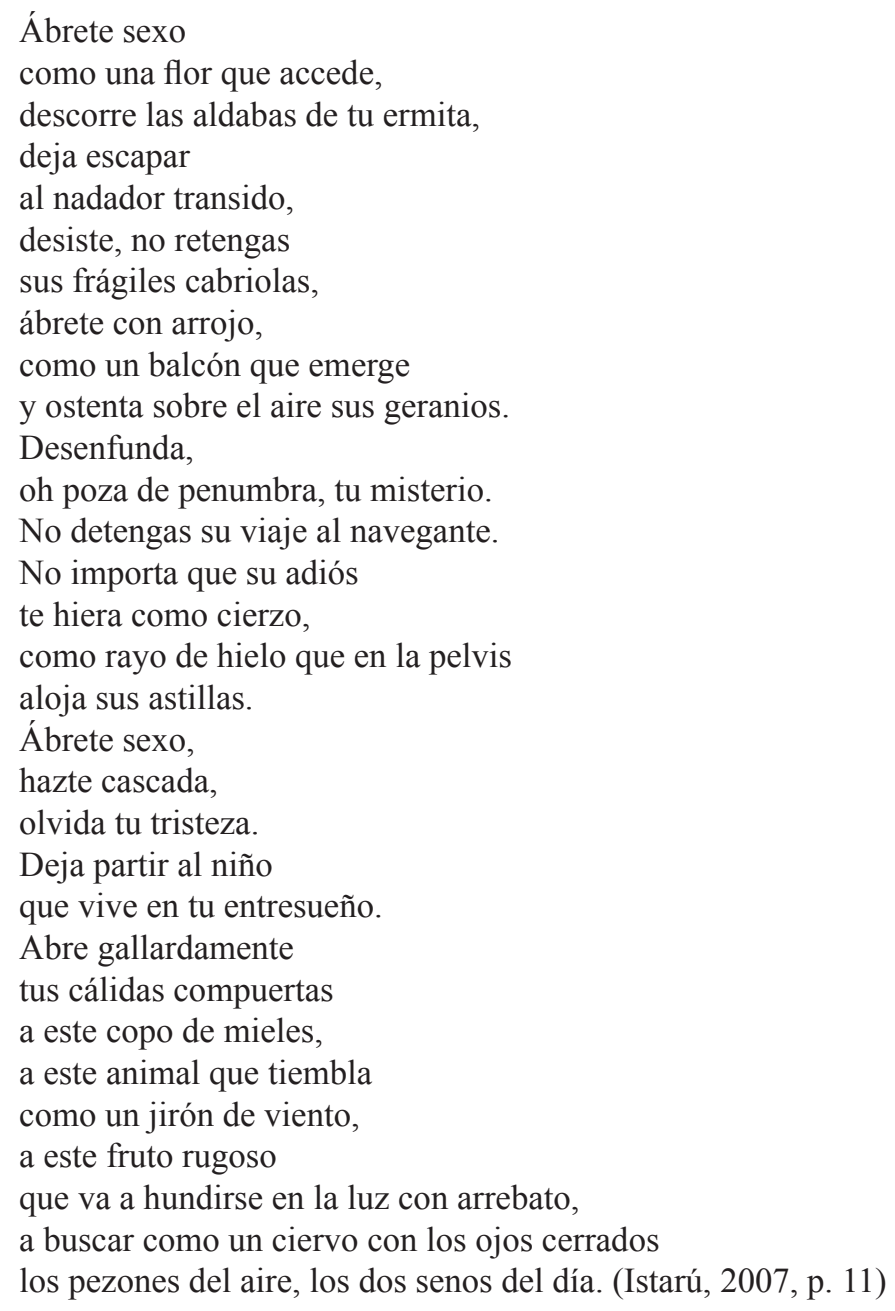

Se expresa la maternidad como un deseo y una plenitud alcanzada por las mujeres que así lo deciden y anhelan, de este modo deja de ser una obligación, el sine qua non femenino y pasa a ser el placer, la apropiación y disfrute de la cualidad creadora que poseen las mujeres. 


\section{La ruptura como característica de la poesía centroamericana contemporánea}

Como segundo punto, se plantea la ruptura, ya tan mencionada. El hecho mismo de escribir es una transgresión, como ya se ha analizado, pero no se queda allí, pues los versos son un enfrentamiento, un reto y un resquebrajamiento a la apolillada ideología patriarcal; por lo tanto, las mujeres escritoras -en general- y con énfasis las centroamericanas contemporáneas exigen un alto a la discriminación, explotación y ninguneo histórico sobre el género femenino.

Como muestra se citan los poemas "Golpe al silencio", de la nicaragüense Blanca Castellón y “Tepresto mivoz”, de la costarricense Arabella Salaverry, respectivamente:

Llegó la hora.

Pervirtamos al silencio.

Pintémosle la boca en rojo.

Embardunémoslo de señales.

De sentimientos jadeantes.

Cubramos su timidez con amapolas frescas.

Entrenemos palabras para aturdirlo.

Vámonos de farra con el silencio.

Emborrachémoslo.

No nos importe su acostumbrada anemia.

Olvidemos su pedantería.

Carguémoslo en hombros.

Entérese de una vez que todo cambia.

Que sea humilde.

Que haga a un lado su afamada mutismería.

Que estalle en gritos como los hijos de la madre tierra. (Ramírez, 2011, p. 308)

Te presto mi voz hermana

Te presto la escasa lucidez

de este siglo vestido de torturas

Te presto mareas

por si se te ocurre deshacer las rocas

Te presto lo visceral del grito de algunos animales

los que habitan el destierro

los que doblan el recodo del olvido

Te presto también mi voz

para que hablés por ejemplo

de los espejos donde no se refleja tu impotencia

Para que denunciés la presencia invisible de tus sueños

Para que nombrés el pan ausente que frecuenta tu mesa 
Te presto mi voz para que hablés en nombre de los niños borrados y mencionés si te parece su desesperada esperanza

Te presto mi voz para que denunciés la fría bayoneta de la muerte invitada imprescindible de las guerras Te presto lo que tengo y lo que no tengo Lo que soy y lo que quisiera ser Lo que el tiempo ha dejado de lo humano lo que los dioses han perdido en el camino Te presto estos poemas. (Salaverry, 2009, p. 33)

De esta forma se evidencia la necesidad de elevar un grito -casi desesperadocontra la injusticia, los roles implantados, tan a disgusto a las mujeres, y (re) apropiarse de sí mismas, de su ideología y su potestad de ser, a pesar de que se contradiga a los planteamientos sociales previamente establecidos. La voz, el poema mismo, se convierte en un medio de evidenciar las injusticias, de retar al poder por medio de una actitud contestataria ante la situación social padecida por las mal llamadas minorías, entre las cuales se encuentran las mujeres.

\section{El humanismo y la poesía centroamericana}

Como último punto, se propone la relación entre los temas anteriores y el humanismo, tercera temática del título que encabeza esta exposición. Si nos guiamos por los conceptos tradicionales del término, las humanidades -creaciones de los seres humanos que dejan huella en el tiempo y nos acercan a la cultura y la ciencia- la literatura, su estudio, análisis y entendimiento son formas intrínsecas del humanismo.

Pensándolo desde la perspectiva del Nuevo humanismo, entendido este desde la concepción de John Brockman como "una síntesis multidisciplinar donde la palabra "humanismo" recupera el sentido de intelectualidad global y conciencia holística que tuvo en el pasado. Son estos "nuevos humanistas" quienes, al combinar ciencias y letras, conforman en la actualidad la vanguardia del pensamiento moderno". (Brockman, 2008, p. 211), se demuestra la literatura centroamericana contemporánea como un espacio de discusión sobre temas latinoamericanos, contemporáneos, que afectan a las personas involucradas en el entorno -es decir un tema social- y donde se incluyen a las mal llamadas minorías -los otros, en caso particular, las otras-. 


\section{Consideraciones finales}

Gracias al estudio de esta temática, nos acercamos a las voces silenciadas históricamente por el patriarcado y que cobran valor en la época actual por medio de la escritura, de la visibilización de las mujeres en el plano literario, método para levantar la voz y enfrentar a la sociedad discriminatoria con el género femenino, históricamente implantada.

Por tanto, se propone la escritura femenina contemporánea de Centroamérica como un espacio para exorcizar los miedos de una sociedad inmersa en el patriarcado que ha minimizado la figura de la mujer, dejándola en el silencio, en un rincón, cumpliendo sus deberes de madre y esposa por imposición, dictándoles la forma de vestir, ser, comportarse y actuar. Gracias a esta producción literaria se da a conocer todo el potencial creador, intelectual y físico de las mujeres, dándose un (re) conocimiento de sus capacidades como sujeto autónomo y empoderado.

La voz autoral femenina se comprende, asimismo, como un espacio donde confluyen los deseos, el placer, la corporeidad, la libertad y el enfrentamiento a las imposiciones sociales desfavorables para las minorías, lo cual se transforma en un tema de discusión del Nuevo humanismo, desde el cual se realiza una lucha contra toda forma de discriminación hacia los seres humanos y entendida como una propuesta contemporánea enfocada en la equidad y respeto de los actores sociales.

\section{Referencias}

Ballesteros, L. (1994). La escritora en la sociedad latinoamericana. Cali: Editorial Universidad del Valle.

Belli, G. (2006). Poesía. Guatemala: F\&G Editores

Brockman, J. (2008). El nuevo humanismo y las fronteras de la ciencia. Madrid: Editorial Kairós.

Calvo, Y. (1990). A la mujer por la palabra. Heredia: EUNA.

Fuentes, L. (1999). Penumbra de la paloma. San José: Ministerio de Cultura, Juventud y Deportes.

Istarú, A. (2007). Poesía escogida. San José: Editorial Costa Rica. 
Ramírez, S. (2011). Puertas abiertas. Antología de poesía centroamericana. México: Fondo de Cultura Económica.

Salaverry, A. (2009). Chicas malas. San José: Uruk Editores 